\title{
Modified Core Biopsy Technique to Increase Diagnostic Yields for Well-Circumscribed Indeterminate Thyroid Nodules: A Retrospective Analysis
}

\author{
(D). Han, (D).H. Shin, (DS.Y.Hahn, and (D).L. Oh
}

\begin{abstract}
BACKGROUND AND PURPOSE: The results of conventional core biopsy for some thyroid nodules with indeterminate cytology have still remained indeterminate. The aim of this study was to evaluate whether the ultrasonography-guided core needle biopsy technique containing the nodule, capsular portion, and surrounding parenchyma was more effective than a conventional method in enhancing diagnostic yield for circumscribed solid thyroid nodules without malignant sonographic features.
\end{abstract}

MATERIALS AND METHODS: This retrospective comparative study evaluated 26 thyroid nodules in 26 consecutive patients between 2006 and 2010. They were biopsied by using a conventional method, and 61 nodules from 60 patients were biopsied by using a modified ultrasonography-guided core needle biopsy technique in 2013. The patients enrolled in this study presented with circumscribed solid thyroid nodules without malignant sonographic features, classified as nondiagnostic or atypia/follicular lesions of undetermined significance at previous cytology. The ultrasonography-guided core needle biopsy results of the 2 groups were compared.

RESULTS: The rate of inconclusive ultrasonography-guided core needle biopsy results was $34.6 \%(9 / 26)$ in the conventional group and $11.4 \%(7 / 61)$ in the modified technique group $(P=.018)$. There was no significant difference in the mean size of the nodules between the 2 groups $(P=.134)$. The malignancy rate was 33\% (3/9) for the conventional group and 52\% $(27 / 52)$ for the modified technique group $(P=$ .473). The most common malignant pathology was a follicular variant of papillary thyroid carcinoma and follicular adenoma was the most common benign lesion.

CONCLUSIONS: For circumscribed solid nodules without malignant sonographic features with indeterminate cytology, the ultrasonography-guided core needle biopsy technique containing the nodule, capsular portion, and surrounding parenchyma is more effective in diagnostic yield compared with a conventional method that biopsies the intranodular portion.

ABBREVIATIONS: AUS/FLUS = atypia or follicular lesions of undetermined significance; CNB = core needle biopsy; FNA = ultrasonography-guided fine-needle aspiration; PTC = papillary thyroid carcinoma; US = ultrasonography

D espite the lack of definite malignant sonographic features, solid thyroid nodules showing nondiagnostic or atypia or follicular lesions of undetermined significance (AUS/FLUS) in fine-needle aspiration (FNA) readings by using the Bethesda System for Reporting Thyroid Cytopathology have raised concerns about the diagnosis of malignancy. ${ }^{1-4}$ The management of nodules with nondiagnostic lesions or AUS/FLUS has been a matter of debate. $^{2,3}$ Several studies have suggested that sonography-guided core needle biopsy (US-CNB) helps decrease the frequency of

Received July 20, 2015; accepted after revision November 11.

From the Departments of Radiology (S.H., J.H.S., S.Y.H.) and Pathology (Y.L.O.), Samsung Medical Center, Sungkyunkwan University School of Medicine, Seoul, South Korea.

Please address correspondence to Jung Hee Shin, MD, PhD, Department of Radiology, Samsung Medical Center, Sungkyunkwan University School of Medicine, 81 Irwon-ro, Gangnam-gu, Seoul 06351, South Korea; e-mail: helena35@hanmail.net

http://dx.doi.org/10.3174/ajnr.A4650 inconclusive diagnostic results and improves the rate of accurate diagnoses. $^{5-9}$

US-CNB is safe and well-tolerated, yields a low incidence of complications, and serves as an alternative to FNA for obtaining tissues for diagnosis. ${ }^{710}$ However, its results have remained indeterminate for up to $36 \%$ of the nodules whose cytology is insufficient to differentiate nodular hyperplasia from follicular neoplasm, even after US-CNB. ${ }^{5}$ On ultrasonography (US), circumscribed solid nodules without malignant features are frequently confirmed histologically as nodular hyperplasia, a follicular neoplasm (follicular/Hürthle adenoma or carcinoma), a follicular variant of papillary thyroid carcinoma (PTC), or a classic type of PTC. ${ }^{11-14}$

The preoperative diagnosis of PTC would usually be sufficient with FNA because nuclear features are the key to diagnosis. "Follicular neoplasm" is defined as an encapsulated lesion whose growth pattern (microfollicular, macrofollicular, trabecular, or 
another growth pattern) is distinct from that of the surrounding thyroid parenchyma. Nodular hyperplasia is one of the most common pathologies in benign thyroid disease and is characterized by a densely cellular follicular proliferation that lacks a capsule on histology. ${ }^{4,15,16}$ Because nodular hyperplasia may sometimes be considered normal thyroid tissue after core needle biopsy diagnosis, the presence of a capsule and normal parenchyma in the thyroid nodule can be meaningful for the differentiation of a follicular neoplasm from nodular hyperplasia. Nodules with circumscribed solid features only identified on US are diagnosed as indeterminate because they have neither malignant nor benign features. ${ }^{17}$ Moreover, indeterminate FNA of these lesions may lead to an unnecessary diagnostic operation. Thus, circumscribed solid thyroid nodules not associated with other malignant features require the use of $\mathrm{CNB}$ techniques under US guidance other than a conventional method that biopsies the internal portion of the thyroid nodule. One recent study suggested that the use of a $\mathrm{CNB}$ technique that biopsied the capsule of the thyroid nodule and the surrounding parenchyma was useful for the diagnosis of cytologically indeterminate nodules. ${ }^{18}$ However, the authors did not compare the results of the conventional method with those of the modified method or focus on the diagnosis of problematic nodules by using a conventional $\mathrm{CNB}$ method. We evaluated whether the modified $\mathrm{CNB}$ technique was more effective in the diagnostic yield of circumscribed solid nodules without malignant sonographic features with indeterminate cytology compared with a conventional method. Therefore, we compared the inconclusive rate (nondiagnostic or AUS/FLUS rate) and malignant rate of $\mathrm{CNB}$ results between the conventional and the modified technique groups.

\section{MATERIALS AND METHODS Study Design and Patients}

This retrospective study was approved by the institutional review board of our institution, and the requirement for informed consent was waived. However, informed consent for procedures was obtained from patients before they underwent the ultrasonography-guided fine-needle aspiration and US-CNB procedures.

From April 2006 to December 2010, US-CNB was performed on 109 patients with 109 thyroid lesions. Twenty-one patients were excluded because of the absence of a history of ultrasonography-guided fine-needle aspiration. The remaining 88 patients had inconclusive results on initial FNA readings obtained in our institution. Among them, 26 consecutive patients presented with 26 thyroid nodules, which were circumscribed solid nodules on US without typical malignant sonographic features (spiculated margins, microcalcifications, marked hypoechogenicity, and taller-than-wide shape). ${ }^{1,17}$ Twenty-five patients from this study had been included in our prior study by Hahn et al. ${ }^{5}$ At that time, we targeted the internal portion of the thyroid nodule by using USCNB (Fig 1). The inclusion of the thyroid capsule and normal parenchyma had not been contemplated, and these patients were defined as the "conventional group." However, a novel US-CNB technique was routinely and prospectively applied to all thyroid nodule samples from June 2013 onward. The main target tissue for biopsy was a capsular portion, including the lesion and normal parenchyma (Fig 1). From July to December 2013, 180 patients
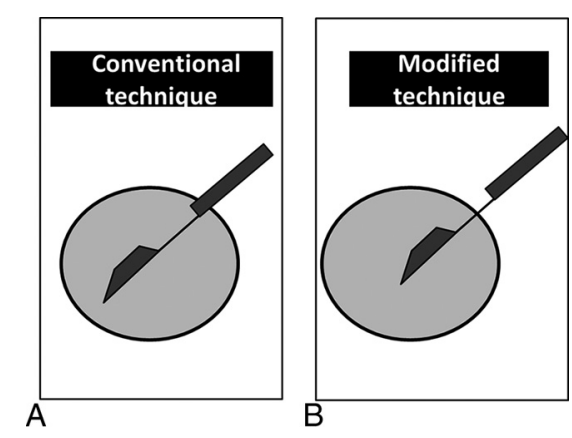

FIG 1. Schematic representation of the conventional and modified US-guided CNB techniques. In the conventional method, the specimen notch of the biopsy needle is confined to the internal portion of the thyroid nodule. In the modified US-CNB technique, the specimen notch of the biopsy needle is placed in the capsule and contains both parenchymal and nodular tissue.

underwent US-CNB. Of these, 60 consecutive patients presented with 61 nodules that were categorized as circumscribed solid nodules without coexistent suspicious features on US or nondiagnostic or AUS/FLUS at previous cytology. All patients included for statistical analysis were surgically diagnosed or followed-up for at least 2 years. We retrospectively reviewed age, sex, and complications after the procedure when present on the medical record. We compared the conclusiveness of CNB results, age, tumor size, malignancy rate, and final pathologic results between the conventional and the modified technique groups.

\section{Ultrasonography and US-Guided CNB Procedures}

All US examinations were performed by using high-resolution ultrasonography equipment (iU22 or HD I5000; Philips Healthcare, Bothell, Washington), with 5- to $12-\mathrm{MHz}$ linear array transducers. US-CNB, including the scanning and interpretation of US images, was performed by 1 of 4 radiologists with $\geq 5$ years' experience. In our practice, US-CNB was sometimes indicated in the diagnosis of thyroid nodules with indeterminate cytology obtained at our or another hospital or if malignant histology other than differentiated thyroid cancer was suspected on US or clinically. In our former study period, the range of indication for USCNB was narrow because an alternative to repeat FNA and ultrasonography-guided fine-needle aspiration was performed at the request of clinicians or patients, even in nodules smaller than 0.5 $\mathrm{cm}$ in the period before the current published guidelines. ${ }^{2,17}$ US$\mathrm{CNB}$ was performed by using a spring-activated, short-throw (1.1-cm excursion) 18-gauge needle (ACECUT; TSK Laboratory, Tochigi-Ken, Japan) by a freehand technique for the 2 study periods. The routine number of thyroid biopsy cores obtained at our institution was 2 or 3 per nodule in the 2 study periods. In the conventional CNB method performed before June 2013, the specimen notch of the biopsy needle and a tissue cutting were confined to the intranodular portion within the thyroid nodule. On the other hand, in the modified US-CNB technique, the specimen notch of the biopsy needle was placed in the capsule and contained both parenchymal and nodular tissue (Fig 1).

\section{Histologic Examination}

Two or 3 specimen cores were fixed in formalin and entirely embedded in a paraffin block. Immunohistochemical staining was 
Table 1: Comparison of ultrasound-guided core needle biopsy for circumscribed solid thyroid nodules without malignant sonographic features with indeterminate cytology

\begin{tabular}{lccc}
\hline & $\begin{array}{c}\text { Conventional } \\
\text { Group }(\boldsymbol{n}=\mathbf{2 6})\end{array}$ & $\begin{array}{c}\text { Modified Technique } \\
\text { Group }(\boldsymbol{n}=61)\end{array}$ & $\boldsymbol{P}$ Value \\
\hline Mean age of patients $(\mathrm{yr})$ & $46.6($ range, 34-62) & $49.7($ range, 26-73) & .204 \\
Mean tumor size $(\mathrm{mm})$ & $18.3($ range, 4 39) & $22.3($ range, 7 $~ 60)$ & .134 \\
Inconclusive rate of US-CNB result $^{\text {Malignant rate }}$ & $34.6 \%(9 / 26)$ & $11.4 \%(7 / 61)$ & .018 \\
Mal $^{\mathrm{a}}$ & $33.3 \%(3 / 9)$ & $51.9 \%(27 / 52)$ & .473 \\
\hline
\end{tabular}

The denominator is the number of the nodules that underwent surgical excision.

Table 2: Correlation with results of US-CNB and final surgical pathology of the conventional CNB group ${ }^{\mathrm{a}}$

\begin{tabular}{lcc}
\hline \multirow{2}{*}{$\begin{array}{c}\text { CNB Results by Bethesda } \\
\text { Category }(\boldsymbol{n}=26)\end{array}$} & \multicolumn{2}{c}{ Surgical Pathology $(\boldsymbol{n}=9)$} \\
\cline { 2 - 3 } Class I $(n=0)$ & $\operatorname{Benign}(\boldsymbol{n}=6)$ & Malignant $(\boldsymbol{n}=3)$ \\
Class II $(n=15)$ & - & - \\
Class III $(n=9)$ & $\mathrm{NH}(n=1), \mathrm{LT}(n=1)$ & - \\
Class IV $(n=1)$ & $\mathrm{NH}(n=4)$ & $\operatorname{PTC}(n=1)$ \\
Class V $(n=0)$ & - & $\operatorname{PTC}(n=1)$ \\
Class VI $(n=1)$ & - & - \\
\hline
\end{tabular}

Note:- NH, nodular hyperplasia; LT, lymphocytic thyroiditis; MTC, medullary thyroid carcinoma.

${ }^{a}$ Data are the number of nodules.

Table 3: Correlation with results of US-CNB and final surgical pathology of the modified CNB group ${ }^{a}$

\begin{tabular}{|c|c|c|}
\hline \multirow{2}{*}{$\begin{array}{l}\text { CNB Results by Bethesda } \\
\text { Category }(n=61)\end{array}$} & \multicolumn{2}{|c|}{ Surgical Pathology $(n=52)$} \\
\hline & Benign $(n=25)$ & Malignant $(n=27)$ \\
\hline Class I $(n=0)$ & & - \\
\hline Class II $(n=7)$ & $\mathrm{NH}(n=1)$ & - \\
\hline Class III $(n=7)$ & $\mathrm{NH}(n=2), \mathrm{FA}(n=2)$ & $\operatorname{FVPTC~}(n=2)$ \\
\hline Class IV $(n=35)$ & $\begin{array}{l}\mathrm{FA}(n=17), \mathrm{NH}(n=2), \\
\quad \mathrm{HT}(n=1)\end{array}$ & $\begin{array}{l}\operatorname{FVPTC}(n=7), \mathrm{FC}(n=5), \\
\text { FVPTC in NH }(n=1)\end{array}$ \\
\hline Class $\vee(n=1)$ & - & $\operatorname{FVPTC}(n=1)$ \\
\hline Class VI $(n=11)$ & - & $\begin{array}{l}\operatorname{PTC}(n=8), \operatorname{FVPTC}(n=2), \\
\quad \operatorname{WVPTC}(n=1)\end{array}$ \\
\hline
\end{tabular}

Note:-FA, follicular adenoma; FC, follicular carcinoma; FVPTC, follicular variant of papillary thyroid carcinoma; HT, Hashimoto thyroiditis WVPTC, Warthin-like variant of papillary thyroid carcinoma; NH, nodular hyperplasia.

${ }^{a}$ Data are the number of nodules.

performed when needed by pathologists. However, we did not assess the role of the immunohistochemical results for the contribution to the diagnosis. The diagnosis of $\mathrm{CNB}$ specimens was interpreted by 1 of 6 cytopathologists. One expert with 15 years of experience in thyroid cytopathology supervised the other cytopathologists in questionable cases. Histologic diagnosis on US$\mathrm{CNB}$ reported in 2 study periods was reclassified into the same 6 categories according to the Bethesda system that was used in FNA readings because no international standardization for $\mathrm{CNB}$ reporting is available ${ }^{4}$ : class I, nondiagnostic; class II, benign; class III, AUS/FLUS; class IV, follicular neoplasm/suspicious for follicular neoplasm; class V, suspicious for malignancy; and class VI, malignancy. After the final CNB results, the nodules were divided into a conclusive group (classes II, IV, V, and VI) and an inconclusive group (classes I and III).

\section{Data and Statistical Analysis}

The conclusiveness of CNB results, age, tumor size, and malignancy rate were compared between the conventional and modified technique groups by using Student $t$ and Fisher exact tests, respectively. Data were analyzed by using SAS software, Version 9.4 (SAS Institute, Cary, North Carolina). All $P$ values were 2-sided, and $P<.05$ was considered statistically significant.

\section{RESULTS}

The clinical parameters and final CNB results are summarized in Table 1 . Of the 26 patients in the conventional group (age range, 34-62 years; mean age, 46.6 years $), 3$ ( $11.5 \%)$ were men and $23(88.5 \%)$ were women. Of the $60 \mathrm{pa}$ tients in the modified technique group (age range, 26-73 years; mean age, 49.7 years), 12 (20\%) were men and 48 (80\%) were women. There were no significant differences in age and sex between the 2 groups $(P$ values $=.204$ and .373 , respectively).

The mean size of the 26 thyroid nodules on conventional US-CNB was 18.3 $\mathrm{mm}$ (range, 4-39 $\mathrm{mm}$ ). The mean size of the 61 thyroid nodules by using the modified CNB technique was $22.3 \mathrm{~mm}$ (range, $7-60 \mathrm{~mm})(P=.134)$. None of the patients evaluated had significant complications. In the modified technique, perinodular hemorrhage occurred in 1 patient immediately after US-CNB but subsided after manual compression.

All specimens obtained by using the 2 US-CNB methods demonstrated adequacy for diagnosis. The $\mathrm{CNB}$ results according to the Bethesda system recommended for practical use showed class II in $15(57.7 \%)$ cases, class III in $9(34.6 \%)$ cases, class IV in $1(3.8 \%)$ case, and class VI in $1(3.8 \%)$ case for the 26 nodules biopsied in the conventional group and class II in 7 (11.4\%) cases, class III in $7(11.4 \%)$ cases, class IV in $35(57.4 \%)$ cases, class V in $1(1.6 \%)$ case, and class VI in $11(18.0 \%)$ cases for the 61 nodules biopsied in the modified method group, respectively. The rate of inconclusive US-CNB results was $34.6 \%$ (9/26) by using the conventional method and $11.4 \%$ (7/61) by using the modified technique $(P=.018)$.

Surgical pathology on excision was present in 9 of 26 nodules in the conventional group and in 52 of 61 nodules in the modified technique group (Tables 2 and 3). The malignancy rate by surgical pathology was $33.3 \%$ (3/9) in the conventional group and $51.9 \%$ $(27 / 52)$ in the modified technique group $(P=.473)$, but this difference was not statistically significant. In the conventional group, surgical pathologies included nodular hyperplasia in 5 cases, chronic lymphocytic thyroiditis in 1 case, classic PTC in 2 cases, and medullary thyroid carcinoma in 1 case (Fig 2). In the modified technique group, final pathology in 52 patients included nodular hyperplasia in 5 cases, follicular adenoma in 19 cases, nodular Hashimoto thyroiditis in 1 case, follicular variant of PTC in 13 cases, classic PTC in 8 cases, follicular carcinoma in 5 cases, and Warthin-like variant of PTC in 1 case (Fig 3).

Of the circumscribed solid nodules without malignant US 

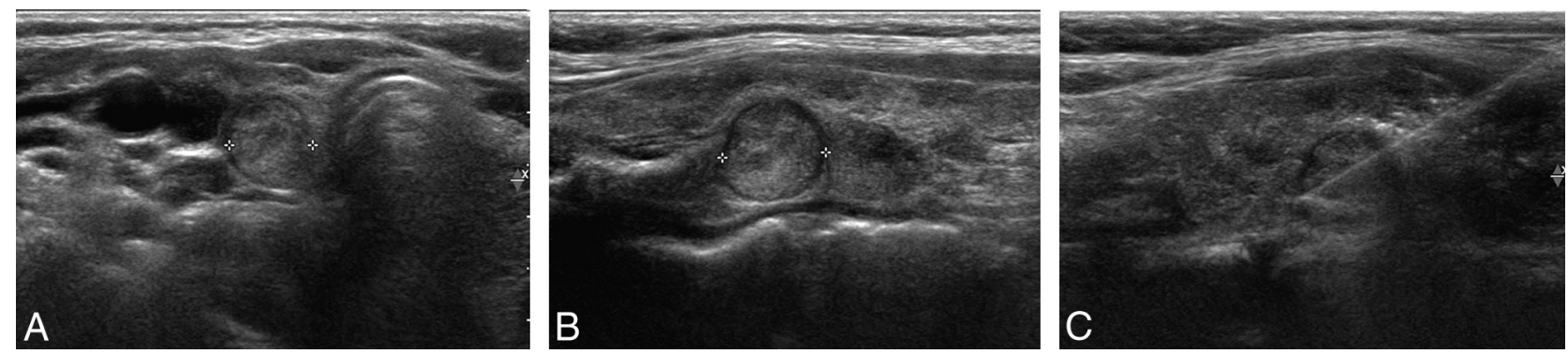

FIG 2. Ultrasound images of a 42-year-old woman who underwent conventional US-CNB. Transverse $(A)$ and longitudinal (B) sonograms demonstrate a 1-cm circumscribed isoechoic nodule (crosses) in the right thyroid lobe. A previous cytologic result was nondiagnostic. After conventional US-CNB confined to a lesion in the thyroid nodule $(C)$, the diagnosis of nodular hyperplasia or Hürthle cell neoplasm was inconclusive. To differentiate nodular hyperplasia from follicular neoplasm, we performed thyroidectomy, and the final pathology indicated nodular hyperplasia.
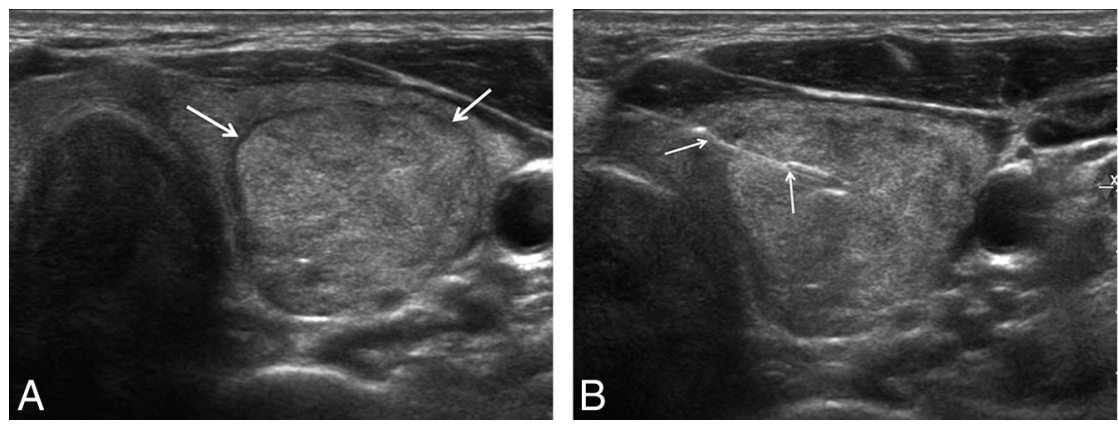

Although a previous study has already described this technique, it did not evaluate its effectiveness compared with a conventional method and concentrate on problematic nodules separately at diagnosis by using routinely performed conventional CNB methods. ${ }^{18}$ These problematic nodules should be diagnosed on US before any intervention. Circumscribed solid nodules without malignant features are considered an indeterminate category on US. ${ }^{17}$ These nodules are a challenge for risk stratification using US, FNA, and even conventional CNB due to the impossibility of capsule assessment.

Previous reports have shown that the $\mathrm{CNB}$ method is more useful than repeat FNA for the evaluation of nodules that are inconclusive on FNA. ${ }^{7-9,19}$ These

features, the most common malignancy was a follicular variant of PTC in 13 (43.3\%) of 30 malignancy cases, and the most frequent benign pathology was follicular adenoma in $19(61.3 \%)$ of 31 benign lesions.

\section{DISCUSSION}

Our study demonstrated that the rate of inconclusive US-CNB results in the modified technique group was significantly lower than that in the conventional group for circumscribed solid nodules without malignant US features (11.4\% versus $34.6 \%$, $P=.004)$. The main issue of the present study was circumscribed solid nodules with indeterminate cytology, which addressed follicular neoplasm rather than PTC because of the presence of nodules without evidence of malignant US features indicating PTC. This modified biopsy technique is essential to differentiate follicular neoplasm from adenomatous nodules because visualization of the capsule in the specimen helps pathologists change their findings from follicular lesions of undetermined significance to follicular neoplasm, while the absence of the capsule implies nodular hyperplasia. This technique can improve identification of surgical candidates. As shown by our results, the percentage of the benign diagnoses decreased in the second cohort by using the modified technique, whereas the percentage of follicular neoplasms increased, as did the percentage of malignancies. studies reported that the rate of inconclusive $\mathrm{CNB}$ results ranged between $0 \%$ and $26 \%$. Recently, Hahn et $\mathrm{al}^{5}$ demonstrated that US-CNB is beneficial for the diagnosis of thyroid nodules with inconclusive US-guided FNA results. However, it is still not helpful for the differential diagnosis in $36 \%$ of nodules that are suspicious for follicular neoplasm on US, as shown by the occurrence of several indeterminate results in the differentiation of nodular hyperplasia from follicular neoplasm even after US-CNB. Nodular hyperplasia is one of the most common benign lesions of the thyroid and does not require further treatment in most patients. ${ }^{4}$ However, follicular neoplasms should be surgically treated because the differentiation of a follicular adenoma from a follicular carcinoma is impossible without the evaluation of the whole capsule. ${ }^{2-4}$ Unfortunately, this modified CNB technique is inadequate to differentiate benign and malignant follicular neoplasms. However, reliable diagnosis of nodules with any evidence of follicular neoplasm via presurgical interventions prevents unnecessary surgery in those patients with simple nodular hyperplasia and gives reassurance to anxious patients who are not candidates for surgery.

In the cases in which surgical pathology was available, the most common malignant subtype in circumscribed solid thyroid nodules without malignant US features with indeterminate cytology was a follicular variant of PTC, with 13 (43.3\%) cases of 30 malignancies. The follicular variant of PTC frequently has cytologi- 
cally inconclusive results without definite malignant features on US. This result supports a previous report in which the follicular variant of PTC showed more benign US features, and the diagnostic rate of PTC on FNA was lower compared with classic PTC. ${ }^{20}$ Further studies about whether CNB is better than FNA for the preoperative diagnosis of the follicular variant of PTC are needed.

Previous reports have suggested that the incidence of conventional CNB-related hematoma was approximately $0 \%-$ $1.5 \% .^{10,21,22}$ In the modified capsular biopsy technique group, 1 patient had subsequent perinodular hemorrhage, which was resolved by manual compression. Perinodular hemorrhages infrequently occur even in FNA by using 23- to 25-gauge needles. ${ }^{23}$ Color Doppler US has to be routinely used to avoid hypervascularized perinodular vessels when the tract for biopsy is determined.

Our study has some limitations. First, this retrospective study compared the results of procedures performed in 2 different periods. Therefore, although some unidentified confounding factors may be present, we could not retrospectively estimate them, and prospective studies would be more adequate in this context. Second, the sample size was small. We did not actively perform US-CNB in the former study period because the management of inconclusive cytologic nodules was routinely performed by using repeat FNA or surgery in our institution. Third, selection bias due to technical problems associated with the biopsies may exist. In case of thyroid nodules large enough to occupy the entire ipsilateral thyroid gland, biopsying the thyroid capsule is not easy because the needle can potentially damage extrathyroidal structures. The modified technique may present limitations in biopsying large nodules and preserving normal parenchyma. The most problematic factor of $\mathrm{CNB}$ in small nodules $(<1 \mathrm{~cm})$ would be target size. If small lesions are well-targeted, the results should be reliable because the notch can be properly positioned within the specimen to encompass $7 \mathrm{~mm}$ of throw.

\section{CONCLUSIONS}

For circumscribed solid thyroid nodules without malignant sonographic features and with indeterminate cytology, the US-CNB technique containing the nodule, capsular portion, and surrounding parenchyma enhances diagnostic yield compared with a conventional CNB method that biopsied only the internal portion of the nodule. This technique reduces the frequency of inconclusive $\mathrm{CNB}$ results and properly selects surgical candidates.

\section{REFERENCES}

1. Kim EK, Park CS, Chung WY, et al. New sonographic criteria for recommending fine-needle aspiration biopsy of nonpalpable solid nodules of the thyroid. AJR Am J Roentgenol 2002;178:687-91 CrossRef Medline

2. Cooper DS, Doherty GM, Haugen BR, et al; American Thyroid Association (ATA) Guidelines Taskforce on Thyroid Nodules and Differentiated Thyroid Cancer. Revised American Thyroid Association management guidelines for patients with thyroid nodules and differentiated thyroid cancer. Thyroid 2009;19:1167-214 CrossRef Medline

3. Gharib H, Papini E, Paschke R, et al. American Association of Clinical Endocrinologists, Associazione Medici Endocrinologi, and EuropeanThyroid Association Medical Guidelines for Clinical Practice for the Diagnosis and Management of Thyroid Nodules. Endocr Pract 2010;16(suppl 1):1-43 CrossRef Medline

4. Cibas ES, Ali SZ. The Bethesda System For Reporting Thyroid Cytopathology. Am J Clin Pathol 2009;132:658-65 CrossRef Medline

5. Hahn SY, Shin JH, Han BK, et al. Ultrasonography-guided core needle biopsy for the thyroid nodule: does the procedure hold any benefit for the diagnosis when fine-needle aspiration cytology analysis shows inconclusive results? Br J Radiol 2013;86:20130007 CrossRef Medline

6. Lee KH, Shin JH, Oh YL, et al. Atypia of undetermined significance in thyroid fine-needle aspiration cytology: prediction of malignancy by US and comparison of methods for further management. Ann Surg Oncol 2014;21:2326-31 CrossRef Medline

7. Park KT, Ahn SH, Mo JH, et al. Role of core needle biopsy and ultrasonographic finding in management of indeterminate thyroid nodules. Head Neck 2011;33:160-65 CrossRef Medline

8. Samir AE, Vij A, Seale MK, et al. Ultrasound-guided percutaneous thyroid nodule core biopsy: clinical utility in patients with prior nondiagnostic fine-needle aspirate. Thyroid 2012;22:461-67 CrossRef Medline

9. Yeon JS, Baek JH, Lim HK, et al. Thyroid nodules with initially nondiagnostic cytologic results: the role of core-needle biopsy. Radiology 2013;268:274-80 CrossRef Medline

10. Screaton NJ, Berman LH, Grant JW. US-guided core-needle biopsy of the thyroid gland. Radiology 2003;226:827-32 CrossRef Medline

11. Rhee SJ, Hahn SY, Ko ES, et al. Follicular variant of papillary thyroid carcinoma: distinct biologic behavior based on ultrasonographic features. Thyroid 2014;24:683-88 CrossRef Medline

12. Kim DW, Jung SJ, Eom JW, et al. Color Doppler features of solid, round, isoechoic thyroid nodules without malignant sonographic features: a prospective cytopathological study. Thyroid 2013;23: 472-76 CrossRef Medline

13. Yoon JH, Kim EK, Youk JH, et al. Better understanding in the differentiation of thyroid follicular adenoma, follicular carcinoma, and follicular variant of papillary carcinoma: a retrospective study. Int J Endocrinol 2014;2014:321595 CrossRef Medline

14. Lee KH, Shin JH, Ko ES, et al. Predictive factors of malignancy in patients with cytologically suspicious for Hürthle cell neoplasm of thyroid nodules. Int J Surg 2013;11:898-902 CrossRef Medline

15. Baloch ZW, Livolsi VA. Follicular-patterned lesions of the thyroid: the bane of the pathologist. Am J Clin Pathol 2002;117:143-50 CrossRef Medline

16. Schreiner AM, Yang GC. Adenomatoid nodules are the main cause for discrepant histology in $\mathbf{2 3 4}$ thyroid fine-needle aspirates reported as follicular neoplasm. Diagn Cytopathol 2012;40:375-79 CrossRef Medline

17. Moon WJ, Baek JH, Jung SL, et al; Korean Society of Thyroid Radiology (KSThR), Korean Society of Radiology. Ultrasonography and the ultrasound-based management of thyroid nodules: consensus statement and recommendations. Korean J Radiol 2011;12:1-14 CrossRef Medline

18. Nasrollah N, Trimboli P, Guidobaldi L, et al. Thin core biopsy should help to discriminate thyroid nodules cytologically classified as indeterminate: a new sampling technique. Endocrine 2013;43: 659-65 CrossRef Medline

19. Na DG, Kim JH, Sung JY, et al. Core-needle biopsy is more useful than repeat fine-needle aspiration in thyroid nodules read as nondiagnostic or atypia of undetermined significance by the Bethesda system for reporting thyroid cytopathology. Thyroid 2012;22: 468-75 CrossRef Medline

20. Kim DS, Kim JH, Na DG, et al. Sonographic features of follicular variant papillary thyroid carcinomas in comparison with conventional papillary thyroid carcinomas. J Ultrasound Med 2009;28: 1685-92 Medline

21. Quinn SF, Nelson HA, Demlow TA. Thyroid biopsies: fine-needle aspiration biopsy versus spring-activated core biopsy needle in 102 patients. J Vasc Interv Radiol 1994;5:619-23 CrossRef Medline

22. Taki S, Kakuda K, Kakuma K, et al. Thyroid nodules: evaluation with US-guided core biopsy with an automated biopsy gun. Radiology 1997;202:874-77 CrossRef Medline

23. Zhang S, Ivanovic M, Nemcek AA Jr, et al. Thin core needle biopsy crush preparations in conjunction with fine-needle aspiration for the evaluation of thyroid nodules: a complementary approach. Cancer 2008;114:512-18 CrossRef Medline 